\title{
UV-MALDI-TOF Mass Spectrometry Analysis of Heparin Oligosaccharides Obtained by Nitrous Acid Controlled Degradation and High Performance Anion Exchange Chromatography
}

\author{
Laurent Bultel, ${ }^{\text {a }}$ Malena Landoni, ${ }^{\text {b Eric Grand, }}$ a Alicia S. Couto, ${ }^{\text {b }}$ \\ and José Kovensky ${ }^{a}$ \\ ${ }^{a}$ Laboratoire des Glucides CNRS UMR 6219, Institut de Chimie de Picardie, Université de Picardie Jules \\ Verne, Amiens, France

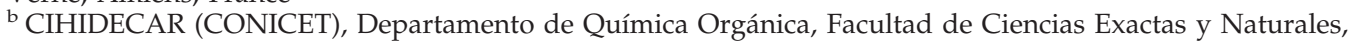 \\ Universidad de Buenos Aires, Buenos Aires, Argentina
}

\begin{abstract}
Nitrous acid degradation of heparin followed by high-performance anion-exchange chromatography (HPAEC) separation and ultraviolet matrix assisted laser desorption/ionization time-of-flight (UV-MALDI-TOF) analysis led to the structural determination of six sulfated oligosaccharides. Three different matrices ( $\alpha$-cyano-4-hydroxycinnamic acid (CHCA), norharmane, and dihydroxybenzoic acid (DHB)) have been used, and the complementary results obtained allowed in most cases to assign the position of sulfate groups. Based on the different cleavages produced on the purified oligosaccharides in source during the MS analysis by the use of the different matrices, this approach provides a new tool for structural analysis. (J Am Soc Mass Spectrom 2010, 21, 178-190) (C) 2010 American Society for Mass Spectrometry
\end{abstract}

G lycosaminoglycanes (GAGs), and more particularly heparan sulfates (HS), have been implicated in the regulation of a broad range of biological processes because of their specific interactions with a large number of proteins [1]. These interactions seem to depend on the number and position of sulfate groups in individual sugar moieties and on the way that sulfated glycosidic units are regrouped to form domains $[2,3]$.

The basic structure of heparin or heparan-like glycosaminoglycans is a disaccharide comprising an uronic acid residue linked $1 \rightarrow 4$ to a glucosamine. It is repeated many times to form heterogeneous mixtures of chains with different lengths. Various modifications within the basic disaccharide unit, including two possible epimers of the uronic acid (L-iduronic and D-glucuronic), sulfation at the N, 3-O, 6-O position of the glucosamine and $2-\mathrm{O}$ position of the uronic acid, generate a considerable amount of diversity.

Among the existing strategies used in current glycobiology to study HS, genetic approaches have shown that targeting a particular sulfotransferase gene may perturb many sulfation patterns throughout the polysaccharide chain and therefore cannot be used to study the impact of a single structural feature [4]. On the other hand, a number of different chemical and biological

Address reprint requests to Professor J. Kovensky, Laboratoire des Glucides CNRS UMR 6219, Institut de Chimie de Picardie, Université de Picardie Jules Verne, 33 Rue Saint-Leu, 80039 Amiens, France. E-mail: jose. kovensky@u-picardie.fr approaches have led to the generation of size-defined heparin oligosaccharide libraries [5, 6]. However their complete purification and the sequencing analytical and chemical methods used for their characterization are still extremely laborious, complex, and particularly limited by the small amounts of purified products available, compromising the efforts to relate a biological function to a specific sulfation sequence. The limited amounts of pure oligosaccharide fragments obtained also preclude structural characterization by the use of spectroscopic methods such as NMR.

The availability of "soft ionization" techniques pointed to MS as an attractive and prominent analytical technique for structural elucidation. Characterization of heparin, HS, and other GAGs has been performed by fast atom bombardment (FAB) [7-10] and electrospray ionization (ESI) [11-14]. Different approaches using LCESI and tandem mass spectrometry $\left(\mathrm{MS}^{n}\right)$ were designed to differentiate isomeric heparin disaccharides [15], and determine sulfation positions and uronic acid epimerization in chondroitin sulfate oligosaccharides [16], as well as to study the effect of the positions of sulfate groups on heparin binding $[2,17]$. Electron detachment dissociation has been used to produce abundant glycosidic and crosslinking fragmentation, revealing sites of sulfation on GAG oligosaccharides [18, 19].

Nowadays, matrix assisted laser desorption/ionization time-of-flight mass spectrometry (MALDI-TOF MS) seems to have become the most appropriate method for the analysis of sulfated oligosaccharides. As an 
example, using ultraviolet matrix assisted laser desorption/ionization time-of-flight mass spectrometry (UV-MALDI-TOF MS) in the negative ion mode, sulfated $\mathrm{GlNNAc}_{2} \mathrm{Man}_{3}$ to $\mathrm{GlCNAc}_{2} \mathrm{Man}_{9}$ species were identified on N-glycosidic chains of cruzipain, in Trypanosoma cruzi [20]. Sulfated N-linked glycans from thyroidstimulating hormone have also been analyzed by MALDI-MS by an in-gel release method [21]. The glycans were mainly sulfated hybrid and biantennary complex structures, and a sulfate group was identified at the 4-position of a galactose residue.

For glycosaminoglycans, the polyanionic nature of glycosidic chains makes more difficult to obtain exploitable results and their understanding. Recently [22], a MALDI MS strategy has been optimized for the analysis of high sulfated GAG-derived oligosaccharides, using a crystalline matrix nor-harmane and an ionic liquid 1-methylimidazolium $\alpha$-cyano-4-hydroxycinnamate matrix. The maximum number of sulfate groups was found using the ionic liquid matrix, whereas MALDI-TOF/ TOF MS/MS experiments allowed the determination of the position of some sulfate groups. However, new improvements are still required before glycomics becomes a routine methodology as proteomics. The intrinsic complexity of oligosaccharide structures seems to lead to specific oligosaccharide-type methods rather than general approaches.

New ionic liquid matrices optimized for MALDI-MS of sulfated, sialylated, and neutral oligosaccharides and glycopeptides have also been reported [23]. 1,1,3,3Tetramethylguanidinium (TMG) salts of $p$-coumaric acid and of $\alpha$-cyano-4-hydroxycinnamic acid (CHCA) have been used in both positive and negative mode and applied to carrageenan oligosaccharides. This method allowed the detection of $1 \mathrm{fmol}$ of neutral and anionic oligosaccharides. In addition, UV-MALDI-TOF-MS has been successfully applied for analysis of DS and CS oligosaccharides using an ionic liquid matrix [24]. However, all these approaches have to be further developed until a reliable method of analysis of sulfated oligosaccharides may be used in routine determinations. In all cases, finding an ionization method soft enough to retain the labile sulfate groups, but at the same time able to produce sugar ring fragmentations required to obtain information about the precise position of them, remains the main problem $[22,25]$.

In this article, a new approach combining nitrous acid degradation followed by high-performance anionexchange chromatography (HPAEC) separation and UVMALDI-TOF analysis is reported. Nitrous acid chemical degradation of heparin and HS has been widely used to produce oligosaccharides. N-sulfated residues are selectively cleaved at $\mathrm{pH} 1.5$ leading to 2,5-anhydromannose terminal units, while $\mathrm{N}$-acetylated domains are preserved, and O-sulfate groups are not affected [26, 27]. This is a very fast reaction, and after one chromatographic run the fractions obtained have been directly analyzed by MALDI MS. Three different matrices (CHCA, nor-harmane and $\mathrm{DHB})$ have been used for the MS analysis, and the complementary results obtained allowed to identify six oligosaccharides and, in most cases, to undoubtedly assign the position of sulfate groups. This approach allows the generation of defined oligosaccharides in a 1-day work. In addition, the information acquired from the variety of spectra obtained by the use of three different matrices under different conditions of analysis was combined to assess their chemical structures. A successful combination of detection, separation, and mass spectrometry analysis may provide a critical advantage in understanding GAG structures.

\section{Experimental}

\section{Materials}

All chemicals and HPLC grade solvents were purchased from Sigma-Aldrich (Saint Quentin Fallavier, France) or Acros Organics (Illkirch, France) and were used without further purification. Water of very low conductivity (MilliQ grade, $18 \mathrm{M}$, Millipore, Bedford, MA, USA) was used. Matrices and calibrating chemicals were purchased from Sigma-Aldrich.

\section{Nitrous Acid Controlled Degradation}

Commercial porcine heparin (Synthex SA, Buenos Aires, Argentina), $100 \mathrm{mg} / \mathrm{mL}$ in $50 \mathrm{mM}$ sodium nitrite, was acidified to $\mathrm{pH} 1.5$ with $6 \mathrm{~N} \mathrm{HCl}$ and maintained at this $\mathrm{pH}$ for $5 \mathrm{~min}$ at room temperature. The resulting oligosaccharides were reduced under alkaline conditions with sodium borohydride.

\section{HPAEC}

HPAEC was performed on a ICS-3000 (Dionex-France, Voisins Le Bretonneux, France) consisting of an autosampler AS50 and an electrochemical detector ED50 working in pulsed amperometric mode for sugar detection (PAD) using $\mathrm{AgCl}$ as the reference electrode and $\mathrm{Au}$ as the working electrode. A series of potentials was applied as follows: $+0.05 \mathrm{~V}$ (from $\mathrm{t}=0$ to $\mathrm{t}=0.40 \mathrm{~s}$, detection began at $\mathrm{t}=0.20 \mathrm{~s}$, and ended at $\mathrm{t}=0.40 \mathrm{~s}$ ), $+0.75 \mathrm{~V}$ (oxidative cleaning, from $\mathrm{t}=0.41$ to $\mathrm{t}=0.60 \mathrm{~s}$ ), $-0.15 \mathrm{~V}$ (from $\mathrm{t}=0.61$ to $\mathrm{t}=1.00 \mathrm{~s}$ ). Oligosaccharides were chromatographed using a ProPac PA1 semipreparative column $(9 \times 250 \mathrm{~mm})$ at $4.7 \mathrm{~mL} / \mathrm{min}$. Injection: $2.5 \mathrm{mg} / 100 \mu \mathrm{L}$. Data were processed with Chromeleon ver. 6.6. Eluent: 0 to $7 \mathrm{~min}: \mathrm{NaOH} 80 \mathrm{mM}$, 7 to 15 min: gradient $\mathrm{NaOH} 80 \rightarrow 100 \mathrm{mM}, 15$ to $60 \mathrm{~min}$ : $\mathrm{NaOH} 100 \mathrm{mM}+$ gradient AcONa $0 \rightarrow 500 \mathrm{mM}$.

\section{MALDI-TOF MS}

All measurements were performed using an Ultraflex II TOF/TOF mass spectrometer equipped with a highperformance solid-state laser $(\lambda 355 \mathrm{~nm})$ and a reflector (Bruker Daltonics GmbH, Bremen, Germany). Samples were measured in the linear and the reflectron modes 
and in the negative ion mode. Spectra were recorded between 0 and $5 \mathrm{kDa}$. One hundred shots were averaged for each spectrum. Calibration was performed with cyclodextrins (cyclohepta-amylose, MW 1135.0 and cycloocta-amylose, MW 1297.1) and a peptide calibration standard from Bruker (angiotensin II, angiotensin I, Substance P, bombesin, ACTH (1-17), ACTH (18-39) and somatostatin). Matrices solutions were prepared by dissolving $1 \mathrm{mg}$ of 2,5-dihydroxybenzoic acid (DHB), nor-harmane, or $\alpha$-cyano-4-hydroxycinnamic acid (CHCA) in $100 \mu \mathrm{L}$ of 3:2 (vol/vol) acetonitrilewater; $10-20 \mu \mathrm{g}$ of each fraction were used for MS. The analyte solutions $(1 \mathrm{mg} / \mathrm{mL})$ were freshly prepared in methanol or in water:methanol 1:1 (vol/vol). Each fraction was analyzed with and without the addition 5 $\mathrm{mM}$ butylammonium formate. Samples were loaded onto the sample probe using the mixture method: the analyte stock solution was mixed with the matrix solution in 1:1 vol/vol ratio. A $0.5 \mu \mathrm{L}$ aliquot of this analyte/matrix solution was deposited onto the stainless steel probe tip and dried at room temperature. Then, an additional portion of $0.5 \mu \mathrm{L}$ was applied to the dried solid layer on the probe, causing it to redissolve partially, and the solvent was left to dry again.

\section{Results and Discussion}

Partial nitrous acid degradation was conducted for exactly 5 min to obtain medium-sized oligosaccharides. The method gave highly reproducible results as it was controlled by analytical HPAEC on a ProPac PA1 column. The elution profile used was totally constant from run to run, and preparative HPAEC allowed the collection of a few $\mu \mathrm{g}$ of each fraction (Figure 1).

The fractions were analyzed by UV-MALDI-TOF in the negative mode using three different matrices (CHCA, nor-harmane, and DHB) with and without the addition of $5 \mathrm{mM}$ butylammonium formate. The addition of ammonium salts has been previously reported to improve sample desorption [28].

Major compounds could be identified in fractions 1 to 6. The other fractions (labeled " $x$ " in Figure 1) were considered to contain unresolved multiple compounds, as complex mixtures of different ions were detected in MS spectra, especially in the molecular weight region. It is interesting to note that no MS/MS was necessary to assign oligosaccharide structures as enough in-source fragmentation was obtained with the different matrices used.

On the ProPac PA1 column, oligosaccharides are eluted as a function of total sulfate content, which also depends on the size of the oligosaccharide. The analyzed fractions were tetra- and hexasaccharides, and for both series the structures deduced from mass spectrometry analysis correspond to the expected order of elution, the more sulfated species being eluted at the higher salt concentrations. This correlation suggests that for diagnostic fragments, little or no desulfation occurred, and therefore the number of total sulfate groups can be determined for the analyzed oligosaccharides. The lack of desulfation observed is likely due to high content of sodium atoms acquired after the HPAEC-PAD separation step, which stabilizes the sulfate groups and partly prevent their elimination during the ionization process [22]. Although all the samples

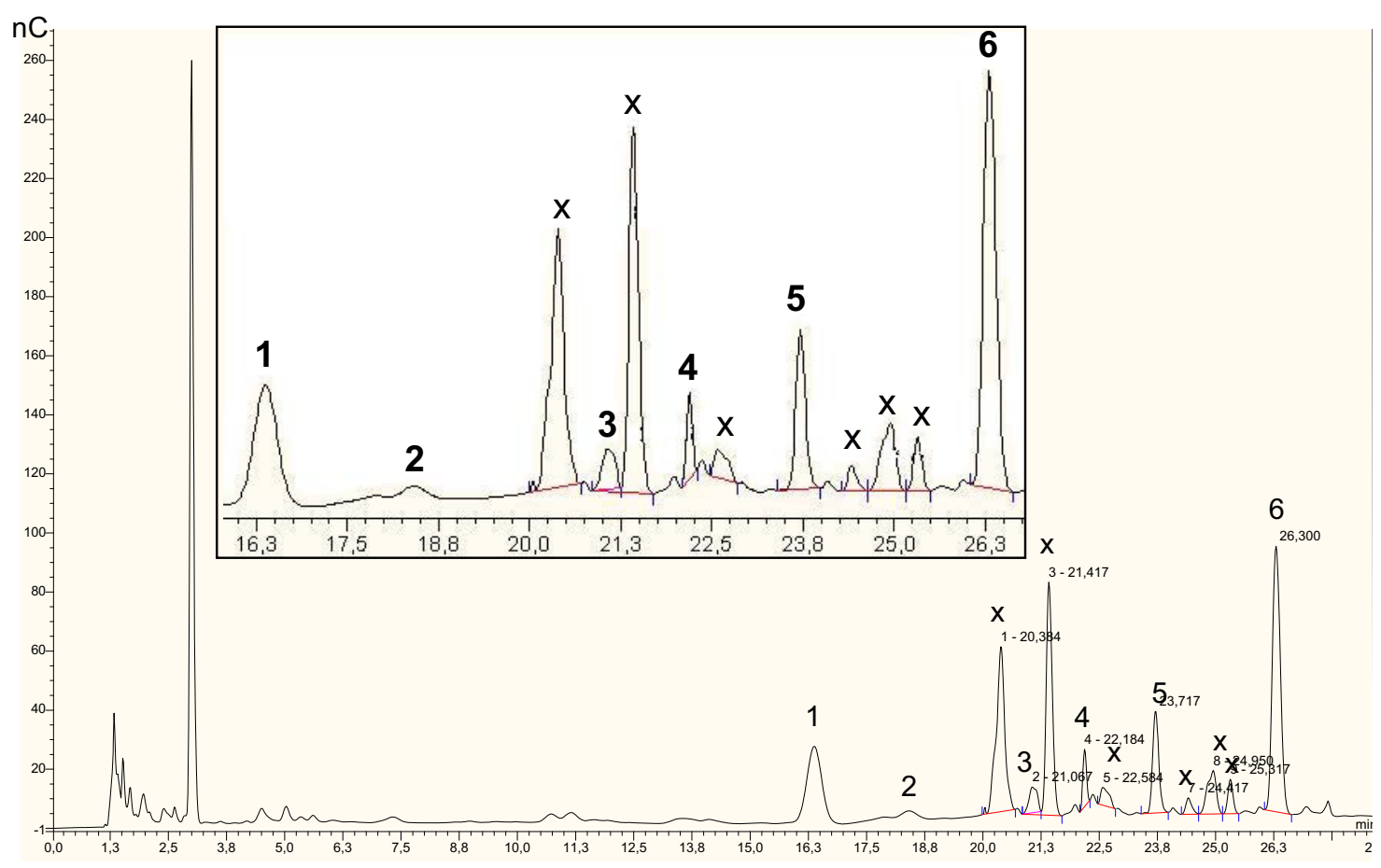

Figure 1. HPAEC-PAD of heparin fragments obtained by nitrous acid degradation. Analyzed fractions are numbered form 1 to $6 .(\times=$ non analyzed fraction) 
were analyzed with the three matrices and all the conditions, only the spectra providing useful and not superposing information were selected for clarity.

\section{UV-MALDI-TOF MS Analysis of the Tetrasaccharide Fractions (Scheme 1)}

Compound 1. The peak corresponding to molecular ion as tetrasodium-monopotassium salt $(\mathrm{m} / \mathrm{z}$ 1165.7) (Figure 2a) allowed the assignment of this compound to a tetrasaccharide carrying four sulfate groups and a $\mathrm{N}$ acetyl group. The peaks corresponding to molecular ion as a trisodium salt $(\mathrm{m} / \mathrm{z} 1104.9)$, as disodium salt $(\mathrm{m} / \mathrm{z}$ 1082.9), were also observed (see Supplementary data, which can be found in the electronic version of this article). Key fragmentations are shown in Scheme 1. In all cases, the fragment nomenclature used is in accordance with Domon and Costello [29]. $B_{2}$ and $Z_{2}$ fragments $(m / z 539.9$ and $m / z 504.4$, respectively) (Figure $2 b$ ) indicated the presence of two sulfate groups in each disaccharide moiety ${ }^{0,3} \mathrm{~A}_{3}\left(\mathrm{~m} / \mathrm{z}\right.$ 642.7) and ${ }^{2,5} \mathrm{~A}_{3}(\mathrm{~m} / \mathrm{z}$ 656.8) (Figure $2 b$ ) fragments are consistent with a 2sulfate at the uronic acid unit (residue 3 from nonre- ducing end), and therefore the second sulfate group must be at the AnhManOH unit, more probably at 6-position than at 3-OH. The remaining sulfate group has to be at the 2-position of the nonreducing uronic acid unit. Other peaks: $m / z 1040.6$ (loss of $\mathrm{CH}_{2} \mathrm{CO}$ from $m / z$ 1082.9, Figure $2 b$ ); $m / z 1003.6$ (loss of $2 \mathrm{SO}_{3}$ from $\mathrm{m} / z$ 1165.7, Figure 2a), m/z $608.3\left({ }^{3,5} \mathrm{~A}_{3}-\mathrm{H}_{2} \mathrm{O}\right.$, see Supplementary data).

Compound 4. Peaks at $m / z 1187.8(\mathrm{M}-\mathrm{H}$, pentasodium salt) and $m / z 1165.7(\mathrm{M}-\mathrm{H}$, tetrasodium salt) (see Supplementary data) could be assigned to a pentasulfated tetrasaccharide. Its elution position in the HPAEC supports this hypothesis compared with the tetrasulfated tetrasaccharide 1 . Fragments ${ }^{0,2} X_{3}(m / z$ 941.7), ${ }^{2,5} \mathrm{~A}_{3}(m / z 781.7)$, and ${ }^{0,2} \mathrm{~A}_{3}(m / z 731.8)$ indicate that both uronic acid residues are 2 -sulfated. The presence of a sulfate group at the AnhManOH unit was suggested by the ${ }^{1,3} \mathrm{~A}_{4}$ peak $(m / z$ 892.7), which requires unsubstituted 3-HO. Ions involving the GlcN unit $\left({ }^{1,5} \mathrm{~A}_{2}\right.$ and ${ }^{1,4} \mathrm{X}_{2}$ at $m / z 548.4$ and 733.8, respectively) allowed the assignment of the positions of the two remaining sulfate groups as a N-sulfate and a 6-sulfate. $\mathrm{C}_{2}(\mathrm{~m} / \mathrm{z}$ 592.8) and

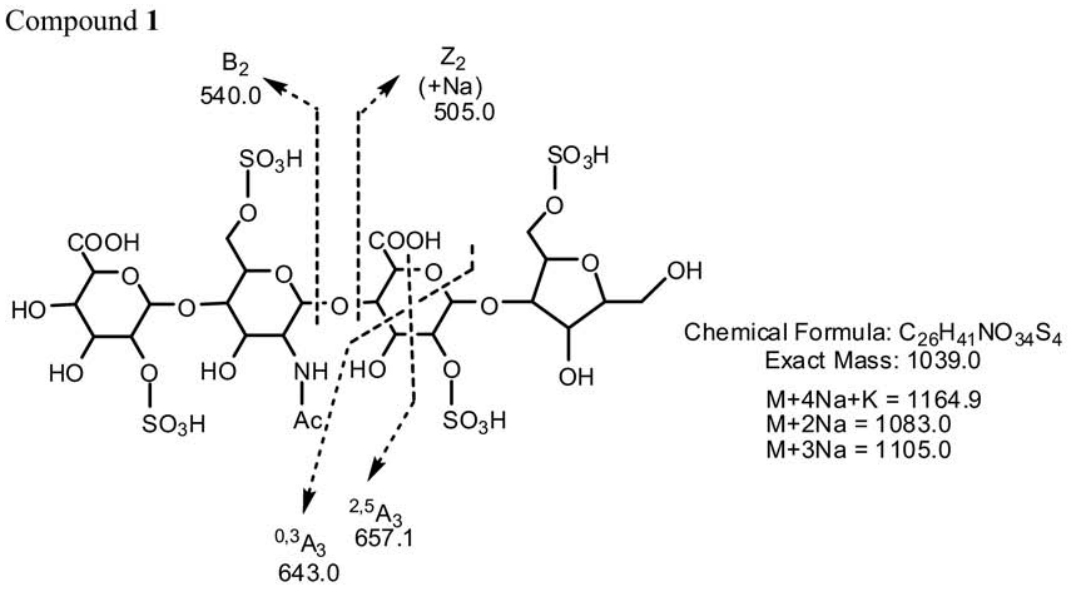

Compound 4

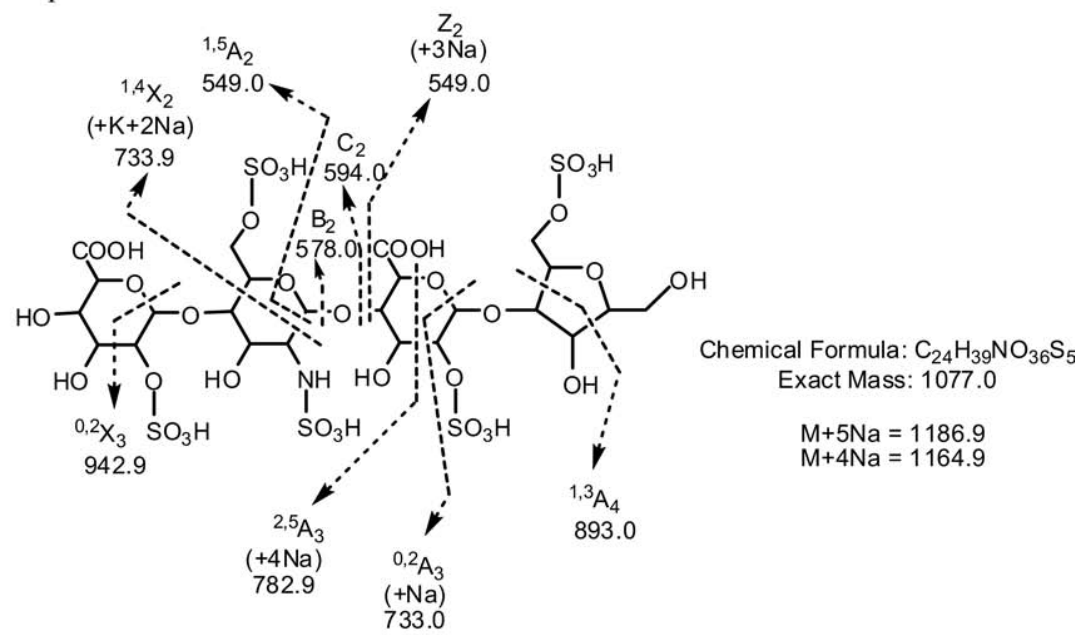

Scheme 1 

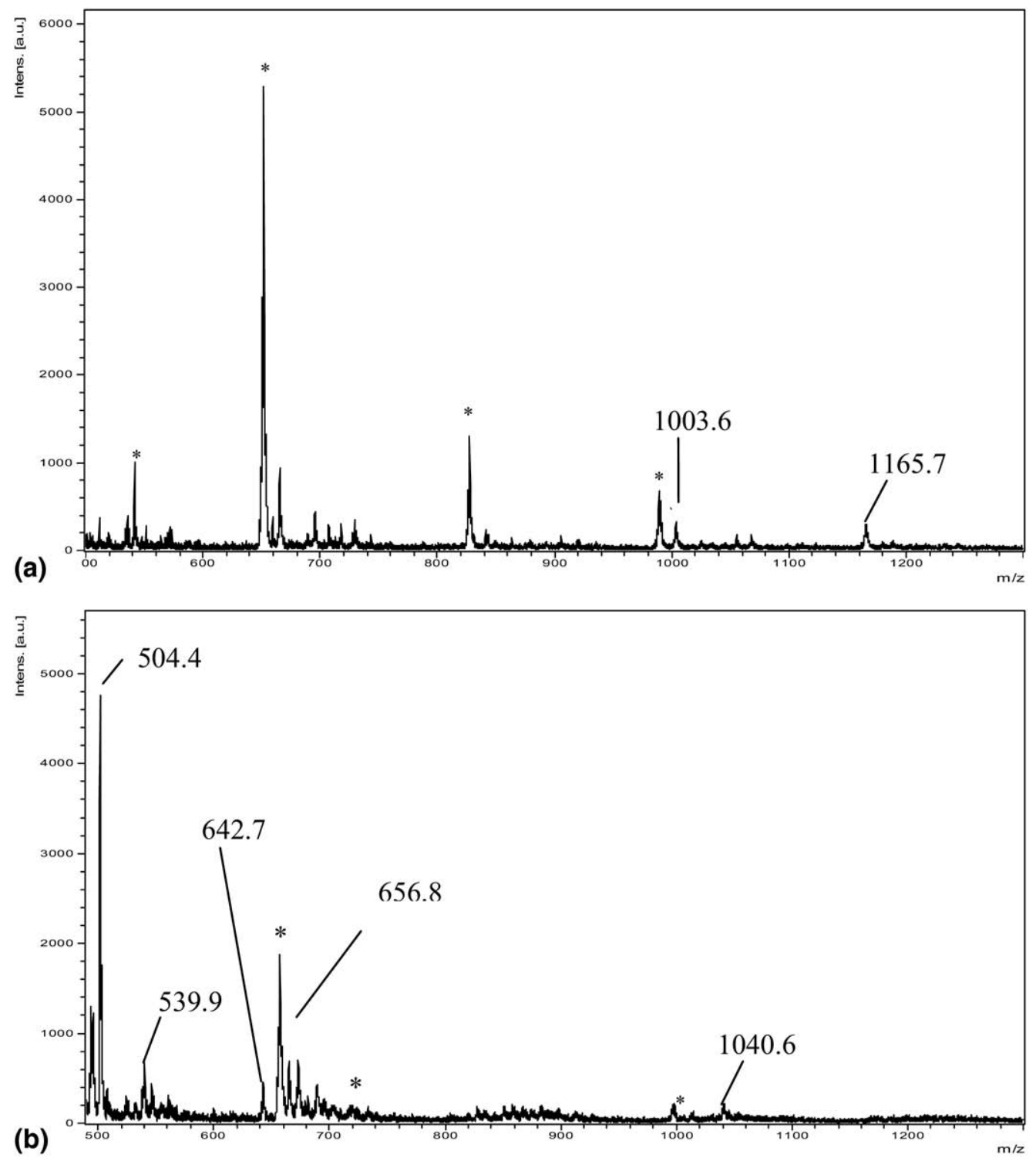

Figure 2. UV-MALDI-TOF spectra in the negative ion mode of Compound 1 using (a) DHB as matrix, (b) DHB with addition of butylammonium formate as matrix. Peaks labeled with an asterisk correspond to adducts of matrix molecules.

$\mathrm{B}_{2}(m / z 576.7)$ fragments confirmed the presence of three sulfate groups on the nonreducing disaccharide moiety. However, signal at $m / z 548.4$ could also be assigned to a $Z_{2}$ fragment bearing three sodium ions analogue to the $Z_{2}$ fragment ( $m / z$ 504.4) obtained for Compound 1. Other peaks: $m / z 1056.2\left(\mathrm{M}-\mathrm{SO}_{3}-\mathrm{CO}\right), m / z$ 965.7, 986.3, $1008.0\left({ }^{0,2} \mathrm{X}_{3}+\mathrm{Na},+2 \mathrm{Na},+3 \mathrm{Na}\right.$, respectively), $756.1\left({ }^{1,4} X_{2}+\mathrm{Na}\right.$, Figure $\left.3 b\right), 614.9\left(C_{2}+\mathrm{Na}\right.$, Figure $\left.3 b\right)$.

\section{UV-MALDI-TOF MS Analysis of the N-Acetyl/ $N$-Sulfate-Containing Hexasaccharide Fractions} (Scheme 2)

Compound 2. Peaks at $m / z 1218.0\left(\mathrm{M}-\mathrm{H}-\mathrm{H}_{2} \mathrm{O}\right.$, monosodium salt) and $m / z 1195.7\left(\mathrm{M}-\mathrm{H}-\mathrm{CH}_{2} \mathrm{CO}\right.$, monosodium salt) suggested a disulfated, mono-N- acetylated hexasaccharide. $\mathrm{C}_{5}-\mathrm{H}_{2} \mathrm{O}$ fragment $(\mathrm{m} / \mathrm{z}$ 1050.3) indicated that the anhydromannitol unit is not sulfated. $\mathrm{C}_{4}$ ion $(\mathrm{m} / z \mathrm{893.1})$ is consistent with a nonsulfated uronic acid linked to the AnhManOH unit (Figure 3a). On the other hand, fragments ${ }^{2,5} X_{5},{ }^{2,5} X_{4}$ and $Z_{4}(m / z$ 1118.8, Figure $3 b, m / z 1017.1$ and 841.5, Figure $3 a$, respectively) together with signal at $m / z 663.8$ $\left(\mathrm{Y}_{3}+\mathrm{Na}-\mathrm{H}_{2} \mathrm{O}\right.$, Figure $\left.3 \mathrm{a}\right)$ support the presence of an acetyl group on the first (from the nonreducing end) glucosamine unit instead of a sulfate group. Therefore, the two sulfate groups must be at the other GlcN. Internal fragments ${ }^{0,3} \mathrm{~A}_{4},{ }^{3,5} \mathrm{~A}_{4}$ and ${ }^{1,4} \mathrm{X}_{2}$ from this unit (at $m / z$ 790.7, 729.7, and 491.0) support substitution at the N,6 positions (Figure 3b). Other peaks: $m / z 1040.2$ $\left(m / z 1081.1+\mathrm{Na}\right.$, Figure 3a); $m / z 956.7\left({ }^{2,5} \mathrm{X}_{4}+\mathrm{Na}\right) ; m / z$ $934.8\left({ }^{2,5} \mathrm{X}_{4}\right) ; 773.7\left({ }^{3,5} \mathrm{~A}_{4}+3 \mathrm{Na}\right) ; 751.7\left({ }^{3,5} \mathrm{~A}_{4}+2 \mathrm{Na}\right)$ 

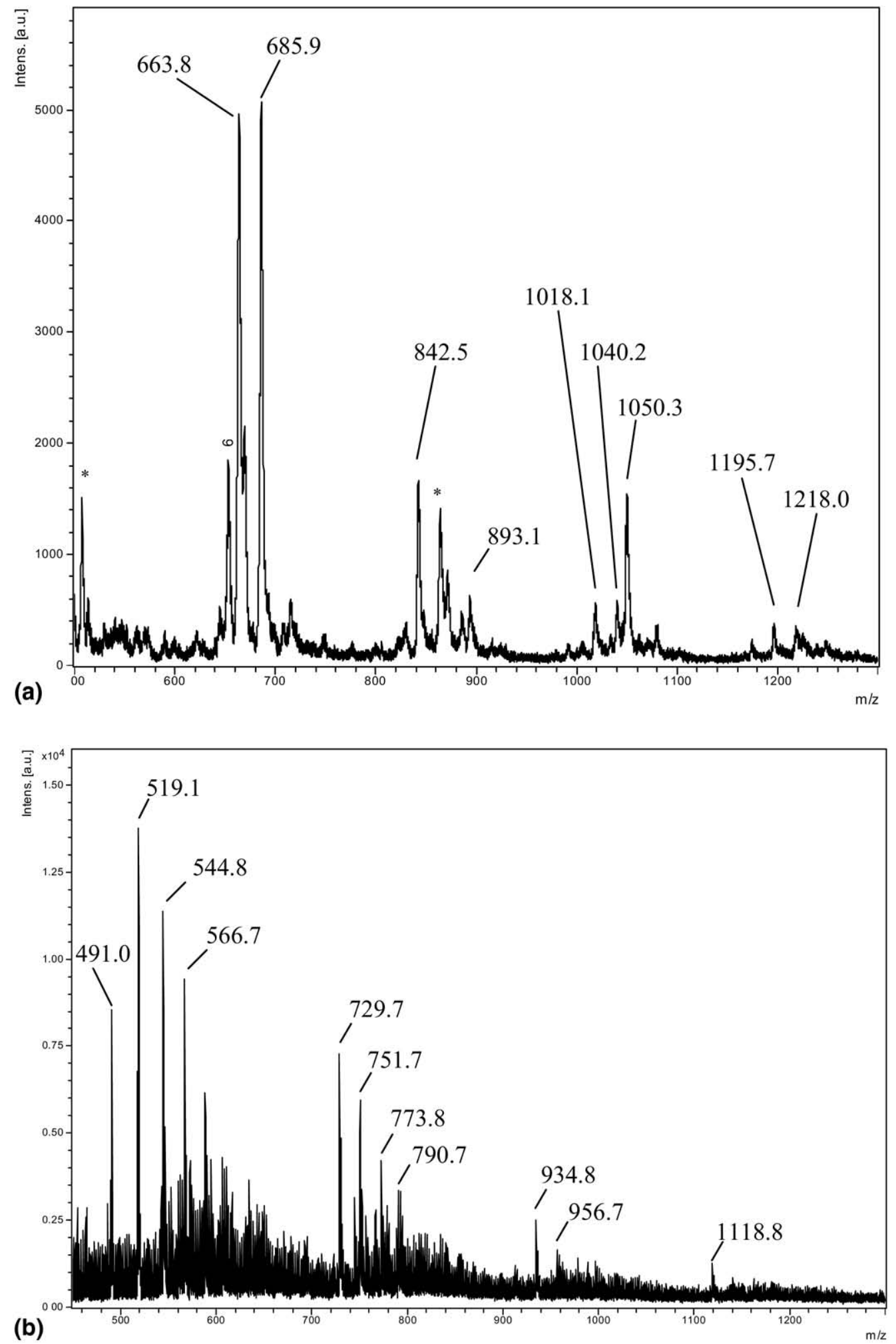

Figure 3. UV-MALDI-TOF spectrum in the negative ion mode of Compound 2 using (a) DHB as matrix, (b) nor-harmane as matrix. Peaks labeled with an asterisk correspond to adducts of matrix molecules.

(Figure 3b); $m / z 685.9(m / z 663.8+\mathrm{Na})$ (Figure 3a), $m / z$ $544.8\left({ }^{3,5} \mathrm{X}_{2}+\mathrm{K}\right) ; m / z 566.7(\mathrm{~m} / z 544.8+\mathrm{Na})$ (Figure 3b).

Compound 3. The molecular ion observed $(m / z$ 1505.8) would correspond to the tetrasodium salt of a tetrasul- fated, di-N-acetylated hexasaccharide, and $m / z 1526.8$ to the corresponding pentasodium ion. ${ }^{2,5} \mathrm{X}_{5}$ anion $(\mathrm{m} / \mathrm{z}$ 1342.9) supports this hypothesis. $Y_{5}$ ion $(m / z$ 1329.0) suggested that the nonreducing end is not sulfated and ${ }^{0,2} \mathrm{X}_{4}$ fragment $(\mathrm{m} / \mathrm{z} 1165.5$ and $\mathrm{m} / \mathrm{z} 1188.2[\mathrm{~m} / \mathrm{z} 1165.5+$ 
Compound 2

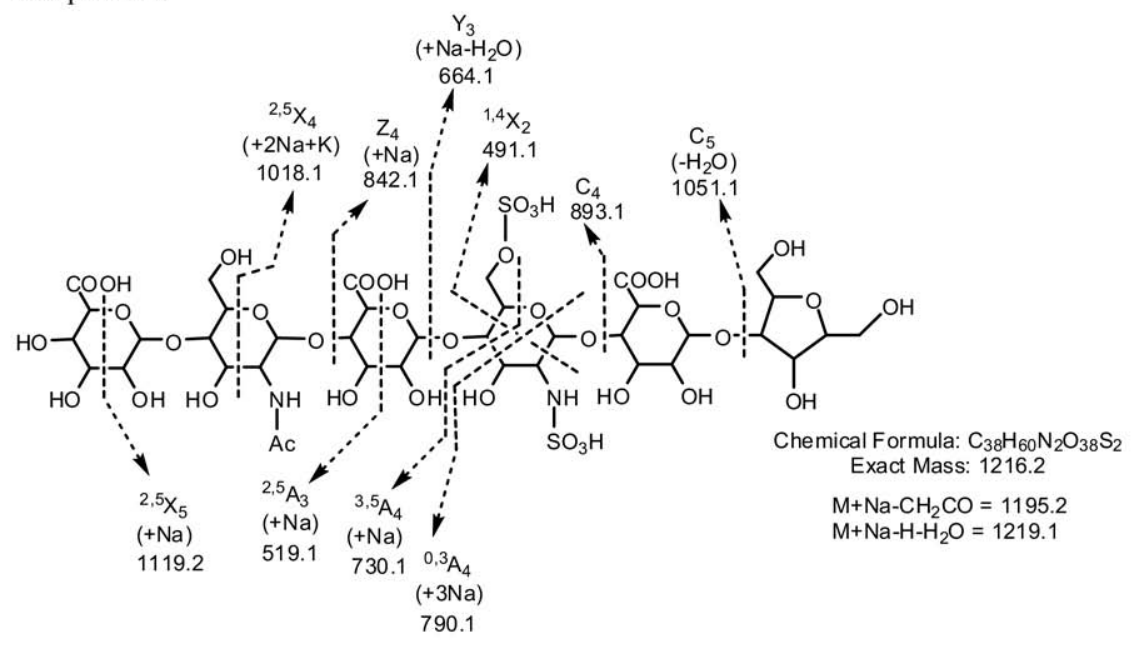

Compound 3

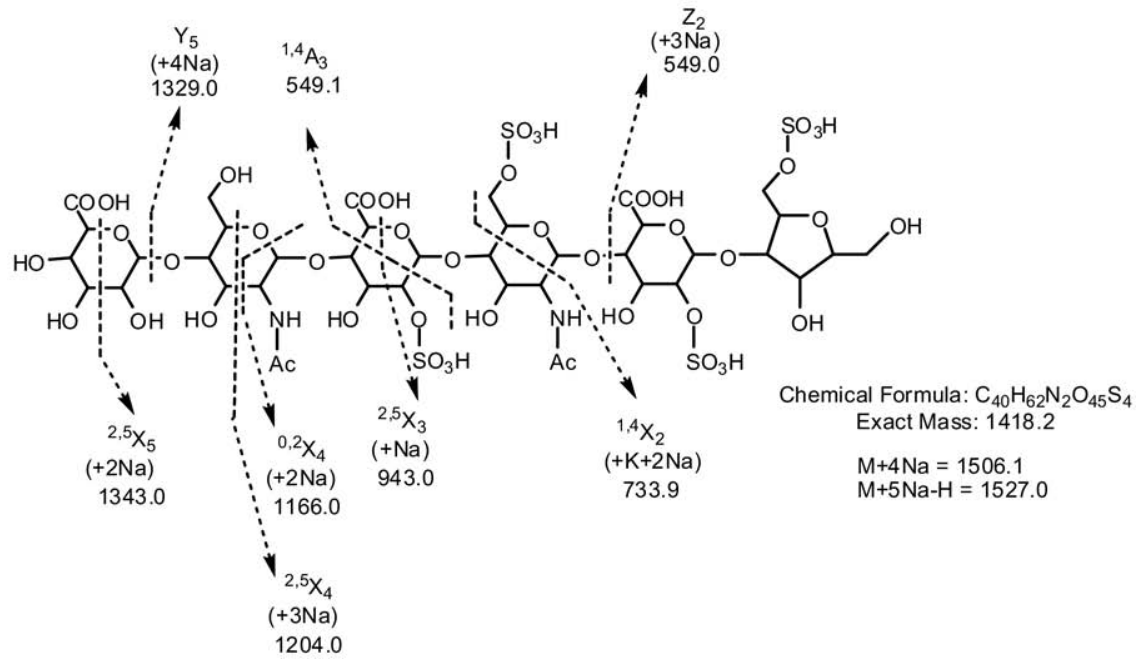

Scheme 2

$\mathrm{Na}$ ) indicated that a sulfate group cannot be located at the nonreducing end disaccharide, as all the four sulfate groups must be on units $4-6$ (Figure $4 \mathrm{a}$ and b). In a similar way, ions at $m / z 1180.5$ and 1204.2 correspond to ${ }^{2,5} \mathrm{X}_{4}$ fragment with or without sodium ion. Also ion ${ }^{2,5} X_{3}$ ( $m / z$ 942.7) supported this statement (Figure $4 \mathrm{c}$ ). The peak at $m / z 548.1$ or 548.4 (Figure $4 a$ and $c$, respectively), assigned to a ${ }^{1,4} \mathrm{~A}_{3}$ cleavage, allow to locate a sulfate group at the 2-position of the second uronic acid residue (unit 3). This fragment also correlates with a $Z_{2}$ fragment as stated for Compound 4, sharing the same anhydromannitol containing disaccharide moiety. ${ }^{1,4} \mathbf{X}_{2}(m / z 733.9$, Figure $4 c)$ fragment is consistent with the pattern of sulfation proposed for the second GlcNAc: 6-sulfation (and not 3-sulfation). The remaining two sulfate groups must be at the reduced disaccharide. One at O-2 of the uronic acid and the other at O-6 (or O-3) of the AnhManOH (as depicted), or both substituting 3-HO and 6-HO of anhydromannitol (in the last case nitrous acid would have cleaved the antithrombin binding site of heparin bearing a
N,3,6-trisulfated glucosamine unit). No additional fragment allowed differentiating between these two possibilities. Other peaks: $m / z 1244.3(\mathrm{~m} / z 1342.9-$ $\mathrm{SO}_{3}-\mathrm{H}_{2} \mathrm{O}$, Figure $\left.4 \mathrm{~b}\right) ; m / z 1407.5\left(\mathrm{M}-\mathrm{SO}_{3}-\mathrm{H}_{2} \mathrm{O}\right.$, Figure $4 \mathrm{~b}) ; m / z 1004.0\left(m / z 1165.5-2 \mathrm{SO}_{3}\right.$, Figure $\left.4 \mathrm{a}\right)$; $m / z 756.1(m / z 733.9+\mathrm{Na}) ; m / z 570.5(\mathrm{~m} / z 548.4+$ $\mathrm{Na}) ; m / z 592.7(m / z 570.5+\mathrm{Na}$, Figure $4 \mathrm{c})$.

\section{UV-MALDI-TOF MS Analysis of the $N$-Sulfate-Containing Hexasaccharide Fractions (Scheme 3)}

Compound 5. The molecular ion appeared at $m / z 1536.9$ for this hexasulfated hexasaccharide (as its disodium salt) and at $m / z 1513.8$ (as its monosodium salt). From mass calculations, no acetyl would be present and, therefore, the two glucosamine residues carry sulfate groups (as N-sulfates). Fragment at $m / z 1351.2\left(\mathrm{C}_{5}+\mathrm{Na}-\mathrm{H}_{2} \mathrm{O}\right)$ indicated that the terminal AnhManOH is not sulfated as in compound 2 (Figure $5 \mathrm{a}) . \mathrm{Y}_{3}$ fragment $(\mathrm{m} / \mathrm{z}$ 837.8, 

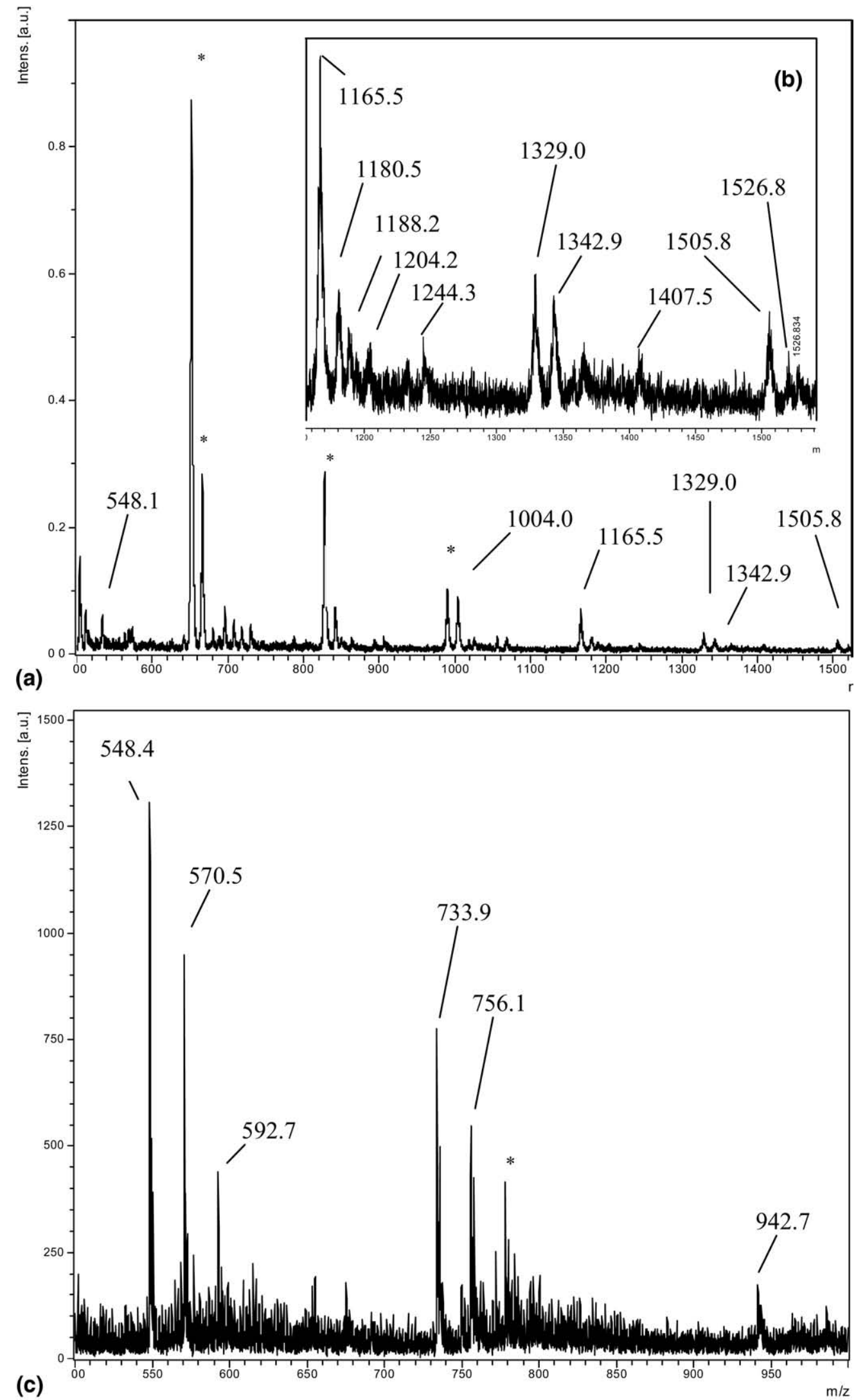

Figure 4. UV-MALDI-TOF spectra in the negative ion mode of Compound 3 using (a) DHB as matrix, (b) expansion of spectrum shown in (a) from $\mathrm{m} / \mathrm{z} 1100$ to 1600, (c) nor-harmane as matrix. Peaks labeled with an asterisk correspond to adducts of matrix molecules. 

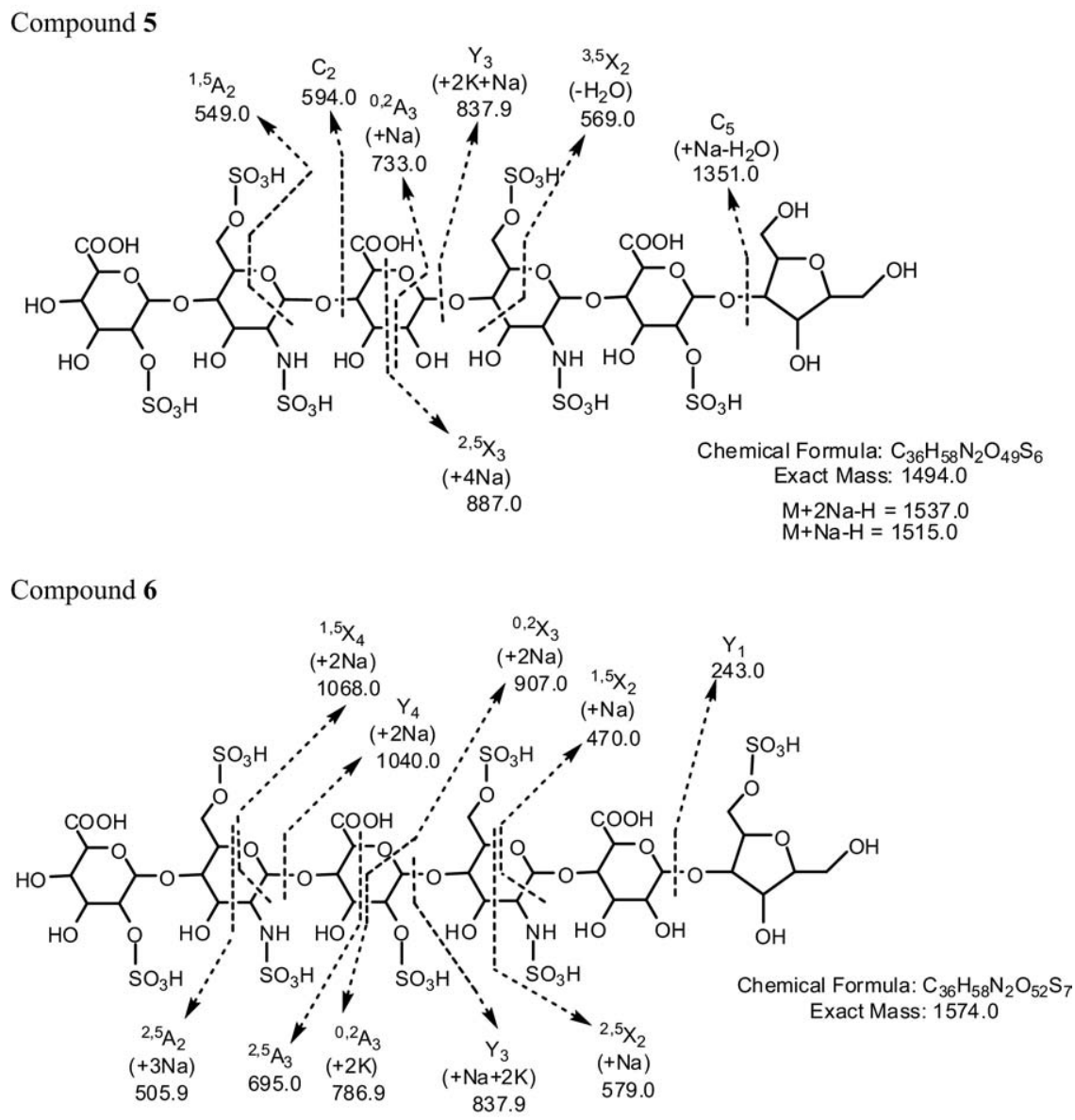

Scheme 3

Figure 5c) corresponds to an anhydromannitol containing trisaccharide bearing three sulfate groups. $C_{2}$ and ${ }^{1,5} \mathrm{~A}_{2}$ (m/z 593.0 and 548.0, respectively, Figure 5b) suggested the presence of two additional sulfate groups at the nonreducing disaccharide. 2-O-sulfation of the uronic acid and 6-O-sulfation of this first GlcNS unit is in fact the most abundant disaccharide in heparin oligosaccharides. Fragment ${ }^{3,5} \mathrm{X}_{2}-\mathrm{H}_{2} \mathrm{O}$ at $\mathrm{m} / \mathrm{z} 568.1$ (Figure 5b) indicated 6-sulfation of the GlcNS unit. The remaining sulfate group may be located at O-2 of the uronic acid residue or (less probable) at O-3 of the glucosamine. In addition, ${ }^{0,2} \mathrm{~A}_{3}$ fragments $(\mathrm{m} / \mathrm{z} 732.4,754.5$ and 776.7, Figure $5 b$ ) are similar to the one obtained for Compound 4.

Other peaks are $m / z 1337.6\left(\mathrm{M}-\mathrm{H}-2 \mathrm{SO}_{3}-\mathrm{H}_{2} \mathrm{O}\right.$, monosodium salt), $\mathrm{m} / \mathrm{z} 1196.6\left(\mathrm{M}-\mathrm{H}-4 \mathrm{SO}_{3}\right.$, monosodium salt), $m / z 1173.7\left(\mathrm{M}-\mathrm{H}-4 \mathrm{SO}_{3}\right.$, free acid), $m / z$ $1011.8\left(\mathrm{M}-\mathrm{H}-6 \mathrm{SO}_{3}\right)$ (Figure 5a), $m / z 902.3\left({ }^{1,4} \mathrm{X}_{3}+2 \mathrm{~K}\right.$ $-2 \mathrm{H}), m / z 886.4\left({ }^{1,4} \mathrm{X}_{3}\right)$ (Figure $\left.5 \mathrm{c}\right), m / z 615.4\left(\mathrm{C}_{2}+\mathrm{Na}\right)$ (Figure 5b).

Compound 6. For this compound, the molecular ion was not observed and the assignment remains speculative. However, the possible structure has been proposed, taking into account adequate fitting to the elution profile on HPAEC. Eluting later than Compound 5,
Compound 6 must bear a minimum of seven sulfate groups. Different fragments observed supported the heptasulfated hexasaccharide depicted in the scheme. ${ }^{2,5} \mathrm{~A}_{2}$ ion $(m / z 505.2$, Figure $6 \mathrm{c})$ indicated a nonreducing uronic acid linked to a 6-sulfated glucosamine, which is obviously N-sulfated too. In support of this assignment, the fragments ${ }^{1,5} X_{4}\left(m / z\right.$ 1068.0, Figure 6a) and $Y_{4}(m / z$ 1039.6, Figure $6 b$ ) have been observed. The same fragmentation, but retaining the negative charge on the other residue $\mathrm{B}_{2}(\mathrm{~m} / \mathrm{z}$ 599.7, Figure $6 \mathrm{c}, \mathrm{m} / \mathrm{z} 665.2$ trisodiated, Figure $6 \mathrm{~b}$ ) was also detected. From the reduced end, peaks at $m / z 578.4$ (as a monosodium ion, Figure $6 \mathrm{~b}$ ) and 557.5 (Figure $6 c,{ }^{2,5} \mathrm{X}_{2}$ ) and $\mathrm{m} / \mathrm{z} 469.6$ (Figure $6 \mathrm{~b}$, ${ }^{1,5} \mathrm{X}_{2}$ ) showed, taking into account that the remaining glucosamine must also be $\mathrm{N}$-sulfated, the presence of one sulfate group at the reduced disaccharide moiety. $\mathrm{Y}_{1}(m / z$ 243.5) fragment supporting the sulfated O-3/ O-6 anhydromannitol residue was also detected (not shown). On the other hand, $Y_{3}$ ion $(m / z$ 837.3, Figure $6 c)$ allowed to locate a sulfate group at the 6-position of the central GlcNS. Moreover, two ions arising from the fragmentation of the same linkages (but leaving the charge at opposite sides), ${ }^{0,2} X_{3}(m / z$ 906.4, Figure 6a) and ${ }^{0,2} \mathrm{~A}_{3}(\mathrm{~m} / \mathrm{z} 786.2$, Figure $6 \mathrm{a})$, were in accordance with 2-sulfation of the central uronic acid unit ${ }^{2,5} \mathrm{~A}_{3}$ fragment $(\mathrm{m} / \mathrm{z}$ 694.3, Figure 6c) confirming the proposed struc- 

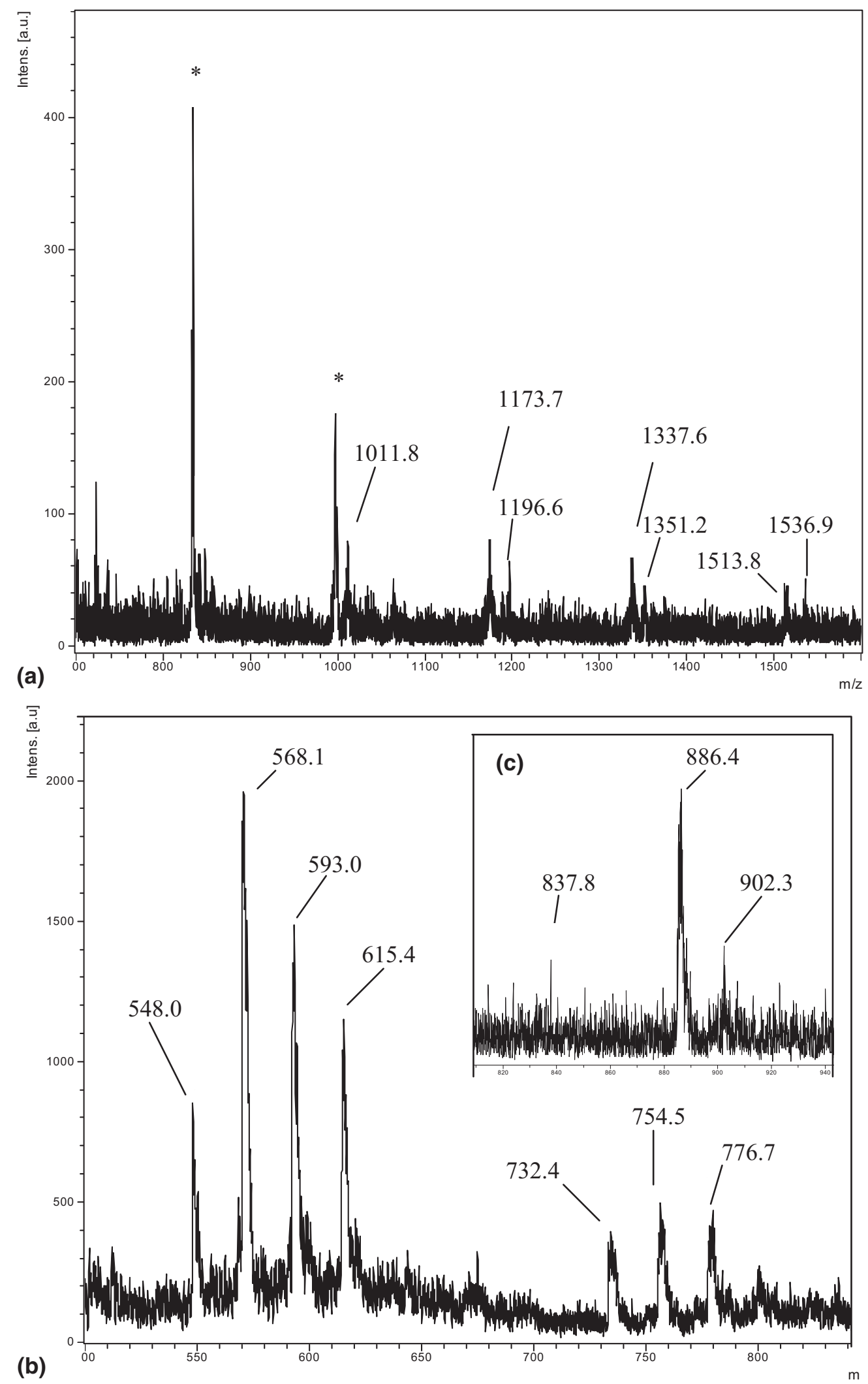

Figure 5. UV-MALDI-TOF spectra in the negative ion mode of Compound $\mathbf{5}$ using (a) DHB as matrix, (b) nor-harmane as matrix, (c) expansion of spectrum shown in (b) from $m / z 800$ to 940 . Peaks labeled with an asterisk correspond to adducts of matrix molecules. 

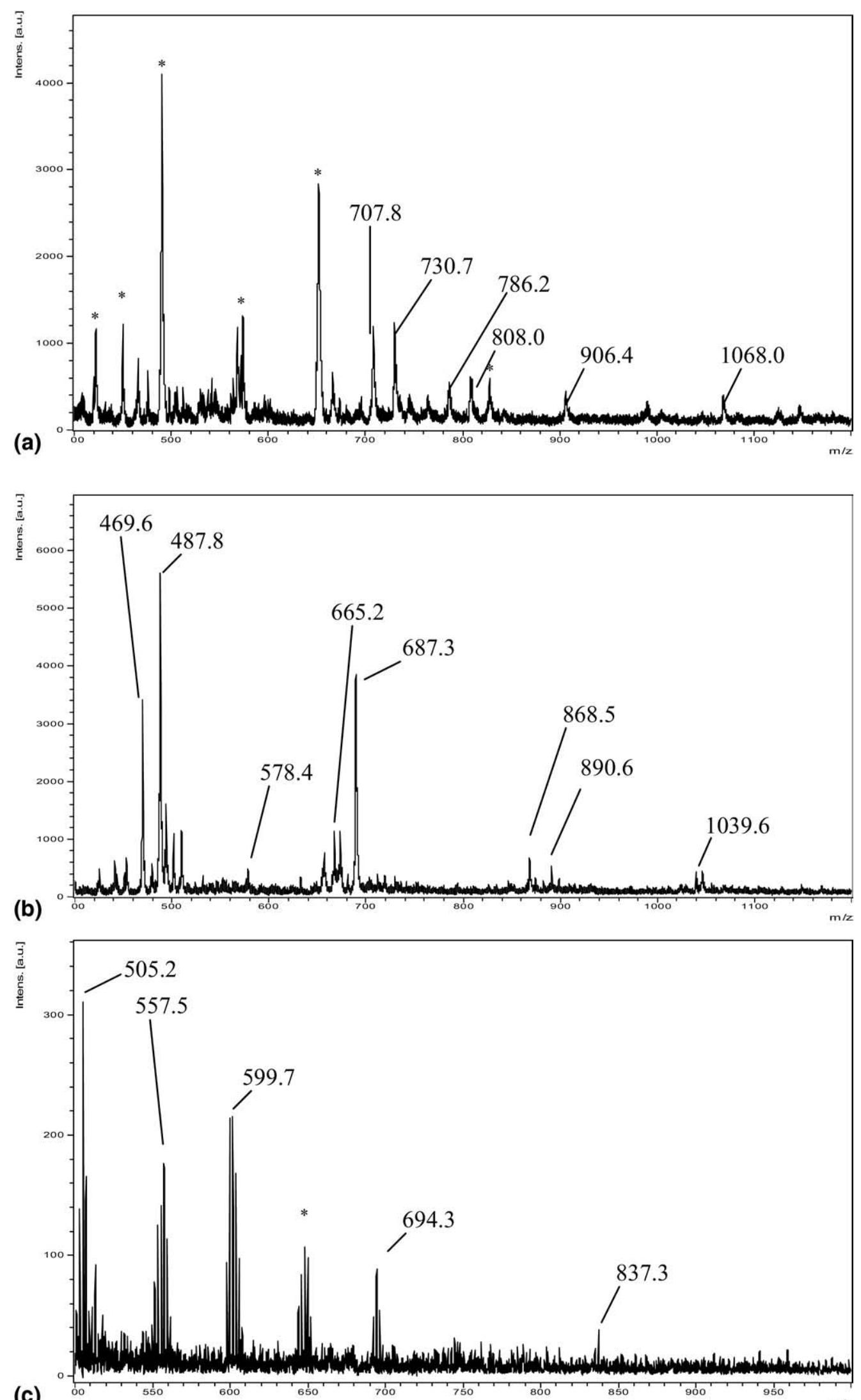

(c)

Figure 6. UV-MALDI-TOF spectra in the negative ion mode of Compound 6 using (a) DHB as matrix (b) DHB with addition of butylammonium formate as matrix, (c) nor-harmane with addition of butylammonium formate as matrix. Peaks labeled with an asterisk correspond to adducts of matrix molecules. 
ture. Other peaks are $m / z 707.8\left({ }^{3,5} \mathrm{~A}_{3}+\mathrm{Na}\right), m / z 730.7$ $\left({ }^{3,5} \mathrm{~A}_{3}+2 \mathrm{Na}\right), m / z 808.0(\mathrm{~m} / z 786.2+\mathrm{Na})$ (Figure 6a), $\mathrm{m} / \mathrm{z} 890.6\left(\mathrm{~m} / \mathrm{z} 1068.0-2 \mathrm{SO}_{3}-\mathrm{H}_{2} \mathrm{O}\right), \mathrm{m} / \mathrm{z} 868.5(\mathrm{~m} / \mathrm{z}$ $890.6-\mathrm{Na}), m / z 687.3\left(\mathrm{~m} / z 868.5-2 \mathrm{SO}_{3}-\mathrm{Na}\right), \mathrm{m} / z$ $487.8\left(\mathrm{~m} / z 665.2-2 \mathrm{SO}_{3}-\mathrm{H}_{2} \mathrm{O}\right)$ (Figure $\left.6 \mathrm{~b}\right)$.

\section{Conclusions}

Optimization of nitrous acid degradation followed by HPAEC separation provided a simple and fast method for obtaining different sulfated oligosaccharides from commercial heparin. Due to its simplicity and low cost, this reaction provides a good alternative to enzymatic degradation, and it has been widely used to obtain oligosaccharides partially modified with an anhydromannitol unit. In this work, we have added an HPAEC separation step followed by UV-MALDI MS analysis in the negative ion mode, using three different matrices allowing the almost complete structural determination of six oligosaccharides. Acidic substituents are stabilized as their sodium salts allowing the detection of ion species from intact molecules. The addition of butylammonium formate, when used, allowed a better desorption of the sample, probably by modifying co-crystallization of the sulfated oligosaccharides with the matrix. No MS/MS analysis was required when the complementary data obtained along the different spectra were analyzed. Only in some cases, the position of one sulfate group remained undetermined between $\mathrm{O}-3$ and an adjacent oxygen, and additional experiments would be necessary to achieve complete structural assignment.

\section{In summary:}

- Although three different matrices were tried, spectra of only two (DHB and nor-harmane) were necessary for structural determination.

- It is known that main fragments from neutral oligosaccharides involve glycosidic linkages (B, C, Y, and Z). In contrast, sulfated oligosaccharides analyzed herein showed main fragments arising from intra-ring cleavages $(\mathrm{A}, \mathrm{X})$. These key fragments for structural assignment seemed favored when the number of sulfate groups in the oligosaccharide increased.

- DHB allowed the molecular ion detection in nearly all cases. This information was useful to determine the total number of sulfate groups present in each glycan. In addition, ions resulting from the loss of sulfate groups were mainly detected.

- Nor-harmane, in contrast, produced mainly fragments. In all cases, ions retaining the sulfate groups were observed making these fragments essential to assign the sulfated positions of each residue. When nor-harmane was not able to produce enough analyte desorption/ionization (Compound 1), fragments useful for structural assignment were produced by the addition of butylammonium formate to DHB matrix.

- The internal 2-O-sulfated hexuronic acids showed multiple intra-ring fragmentations, especially involving C2-C3 linkages $\left({ }^{2,5} \mathrm{X},{ }^{2,5} \mathrm{~A},{ }^{0,2} \mathrm{~A}\right)$, while fragments coming from the nonreducing uronic acid unit were scarcely detected. 6-O-sulfated GlcNAc or $\mathrm{GlcNSO}_{3}{ }^{-}$ units showed mainly $\mathrm{C} 5-\mathrm{O}$ fragmentations $\left({ }^{2,5} \mathrm{X},{ }^{2,5} \mathrm{~A}\right.$, $\left.{ }^{1,5} \mathrm{X},{ }^{1,5} \mathrm{~A}\right)$. In only one case, a fragment involving the anhydromannitol unit was detected $\left({ }^{1,3} \mathrm{~A}_{4}\right.$, Compound 4).

Despite further developments are still necessary before routine glycomic analysis of GAGs becomes available, this approach provides a rapid production of structurally defined oligosaccharides and a fast analysis. However, separation conditions must be optimized to identify all individual components. Our results suggest that this methodology could be profitable to improve knowledge on specific domains of GAG-binding proteins of different sources. The multiple matrices approach reported is useful for a rapid analysis of the sulfation pattern of heparin oligosaccharides, for which the repeating disaccharide unit is well known. Application to other substituted oligosaccharides would require previous knowledge about glycosidic linkages, as this method provides no information about the connection of monosaccharide units.

\section{Acknowledgments}

The authors acknowledge support for this work by the ECOSSecyt program (Action A06S01) of bi-national cooperation. The authors also acknowledge financial contribution of the Centre National de la Recherche Scientifique (CNRS, France), the Ministère Délégué à l'Enseignement Supérieur et à la Recherche (France), and the Consejo Nacional de Investigaciones Científicas y Técnicas (CONICET, Argentina). The Ultraflex II (Bruker) TOF/ TOF mass spectrometer was supported by a grant from ANPCYT, PME 125. A.S.C. is a member of the CONICET; M.L. is a CONICET fellow. The authors thank Dr. David Lesur for his valuable assistance with the HPAEC analysis.

\section{Appendix A Supplementary Material}

Supplementary material associated with this article may be found in the online version at doi:10.1016/ j.jasms.2009.09.025.

\section{References}

1. Raman, R.; Sasisekharan, V.; Sasisekharan, R. Structural Insights into Biological Roles of Protein-Glycosaminoglycan Interactions. Chem. Biol. 2005, 12, 267-277.

2. Naimy, H.; Leymarie, N.; Bowman, M. J.; Zaia, J. Characterization of Heparin Oligosaccharides Binding Specifically to Antithrombin III Using Mass Spectrometry. Biochemistry 2008, 47, 3155-3161.

3. Capila, I.; Linhardt, R. J. Heparin-Protein Interactions. Angew. Chem. Int. Ed. 2002, 41, 391-412.

4. Hacker, U.; Nybakken, K.; Perrimon, N. Heparan Sulphate Proteoglycans: The Sweet Side of Development. Nat. Rev. Mol. Cell. Biol. 2005, 6 , 530-541.

5. Pye, D. A.; Vives, R. R.; Turnbull, J. E.; Hyde, P.; Gallagher, J. T. Heparan Sulfate Oligosaccharides Require 6-O-Sulfation for Promotion of Basic Fibroblast Growth Factor Mitogenic Activity. J. Biol. Chem. 1998, 273, 22936-22942.

6. Guerrini, M.; Naggi, A.; Guglieri, S.; Santarsiero, R.; Torri, G. Complex Glycosaminoglycans: Profiling Substitution Patterns by Two-Dimensional NMR Spectroscopy. Anal. Biochem. 2005, 337, 35-47.

7. Ii, T.; Kubota, M.; Okuda, S.; Hirano, T.; Ohashi, M. Positive-Ion Fast Atom Bombardment Tandem Mass Spectrometry for Characterization 
of Sulfated Unsaturated Disaccharides from Heparin and Heparan Sulfate. Eur. Mass Spectrom. 1995, 1, 11-22.

8. Ii, T.; Kubota, M.; Okuda, S.; Hirano, T.; Ohashi, M. Negative-Ion Fast Atom Bombardment Tandem Mass Spectrometry for Characterization of Sulfated Unsaturated Disaccharides from Heparin and Heparan Sulfate. Glycoconj. J. 1995, 12, 162-172.

9. Mallis, L. M.; Wang, H. M.; Loganathan, D.; Linhardt, R. J. Sequence Analysis of Highly Sulfated Heparin-Derived Oligosaccharides Using Fast Atom Bombardment Mass Spectrometry. Anal. Chem. 1989, 61, $1453-1458$

10. Reinhold, V. N.; Carr, S. A.; Green, B. N.; Petitou, M.; Choay, J.; Sinay, P. Structural Characterization of Sulfated Glycosaminoglycans by Fast Atom Bombardment Mass Spectrometry: Application to Heparin Fragments Prepared by Chemical Synthesis. Carbohydr. Res. 1987, 161, 305-313

11. Desaire, H.; Leary, J. A. Detection and Quantification of the Sulfated Disaccharides in Chondroitin Sulfate Using Ion Trap Tandem Mass Spectrometry. J. Am. Soc. Mass Spectrom. 2000, 11, 916-920.

12. Zaia, J.; Costello, C. E. Compositional Analysis of Glycosaminoglycans by Electrospray Mass Spectrometry. Anal. Chem. 2001, 73, 233-239.

13. Pope, R. M.; Raska, C. S.; Thorp, S. C.; Liu, J. A. Analysis of Heparan Sulfate Oligosaccharides by Nano-Electrospray Ionization Mass Spectrometry. Glycobiology 2001, 11, 505-513.

14. McClellan, J. E.; Costello, C. E.; O'Connor, P. B.; Zaia, J. Influence of Charge State on Product Ion Mass Spectra and the Determination of 4S/6S Sulfation Sequence of Chondroitin Sulfate Oligosaccharides. Anal. Chem. 2002, 74, 3760-3771.

15. Saad, O. M.; Leary, J. A. Delineating Mechanisms of Dissociation for Isomeric Heparin Disaccharides Using Isotope Labeling and Ion Trap Tandem Mass Spectrometry. J. Am. Soc. Mass Spectrom. 2004, 15, 1274-1286.

16. Zaia, J.; Li, X.; Chan, S.; Costello, C. E. Tandem Mass Spectrometric Strategies for Determination of Sulfation Positions and Uronic Acid Epimerization in Chondroitin Sulfate Oligosaccharides. J. Am. Soc. Mass Spectrom. 2003, 14, 1270-1281.

17. Sweeney, M. D.; Yu, Y.; Leary, J. A. Effects of Sulfate Position on Heparin Octasaccharide Binding to CCL2 Examined by Tandem Mass Spectrometry. J. Am. Soc. Mass Spectrom. 2006, 17, 1114-1119.
18. Wolff, J. J.; Amster, I. J.; Chi, L.; Linhardt, R. J. Electron Detachment Dissociation of Glycosaminoglycan Tetrasaccharides. J. Am. Soc. Mass Spectrom. 2007, 18, 234-244.

19. Wolff, J. J.; Laremore, T. N.; Busch, A. M.; Linhardt, R. J.; Amster, I. J. Electron Detachment Dissociation of Dermatan Sulfate Oligosaccharides. J. Am. Soc. Mass Spectrom. 2008, 19, 294-304.

20. Barboza, M.; Duschak, V. G.; Fukuyama, Y.; Nonami, H.; Erra-Balsells, R.; Cazzulo, J. J.; Couto, A. S. Structural Analysis of the N-Glycans of the Major Cysteine Proteinase of Trypanosoma Cruzi. Identification of Sulfated High-Mannose Type Oligosaccharides. FEBS J. 2005, 272, 3803 3815.

21. Wheeler, S. F.; Harvey, D. J. Extension of the In-Gel Release Method for Structural Analysis of Neutral and Sialylated N-Linked Glycans to the Analysis of Sulfated Glycans: Application to the Glycans from Bovine Thyroid-Stimulating Hormone. Anal. Biochem. 2001, 296, 92-100.

22. Tissot, B.; Gasiunas, N.; Powell, A. K.; Ahmed, Y.; Zhi, Z.; Haslam, S. M. Morris, H. R.; Turnbull, J. E.; Gallagher, J. T.; Dell, A. Towards GAG Glycomics: Analysis of Highly Sulfated Heparins by MALDI-TOF Mass Spectrometry. Glycobiology 2007, 17, 972-982.

23. Fukuyama, Y.; Nakaya, S.; Yamazaki, Y.; Tanaka, K. Ionic Liquid Matrices Optimized for MALDI-MS of Sulfated/Sialylated/Neutral Oligosaccharides and Glycopeptides. Anal. Chem. 2008, 80, 2171-2179.

24. Laremore, T. N.; Zhang, F. M.; Linhardt, R. J. Ionic Liquid Matrix for Direct UV-MALDI-TOF-MS Analysis of Dermatan Sulfate and Chondroitin Sulfate Oligosaccharides. Anal. Chem. 2007, 79, 1604-1610.

25. Zaia, J. Mass Spectrometry of Oligosaccharides. Mass Spectrom. Rev. 2004, 23, 161-227.

26. Casu, B. Structure and Biological Activity of Heparin. Adv. Carbohydr. Chem. Biochem. 1985, 43, 51-132.

27. Conrad, H. E. Heparin-Binding Proteins; Academic Press: San Diego, 1998; pp 61-114.

28. Antonopoulos, A.; Favetta, P.; Helbert, W.; Lafosse, M. On-Line Liquid Chromatography Electrospray Ionization Mass Spectrometry for the Characterization of $\kappa$ - and $\iota$-Carrageenans. Application to the Hybrid เ-/ $\nu$-Carrageenans. Anal. Chem. 2005, 77, 4125-4136.

29. Domon, B.; Costello, C. A. Systematic Nomenclature for Carbohydrate Fragmentations in FAB-MS/MS Spectra of Glycoconjugates. Glycoconj. J. 1988, 5, 397-409. 